\title{
Quadruple Electron Storage using Visible Light with Nitrogen-Heterocycles under Metal-Free
}

\section{Conditions}

Aslan, J. M., ${ }^{[a]}$ Yousufuddin, M. ${ }^{[b]}$, Boston, D.J. ${ }^{[a]}$, and MacDonnell F.M. ${ }^{[a]}$

Abstract: A byproduct of the synthesis of 9,11,20,22-tetra-aza-tetrapyrido[3,2-a:2'3'-c:3",2"-I:2"',3"']pentacene (tatpp) is the symmetrical dimer ditatpp, which is linked by a carbon-carbon bond along the central benzene ring. The structure of the dimer has been determined by X-ray crystallography and reveals a dihedral angle of $73^{\circ}$ between the two tatpp units, which is likely due lone pair repulsion on the adjacent aza nitrogens on each tatpp unit. Because of this non-planar geometry, this ditatpp dimer is freely soluble in organic solvents, such as ethanol, very much unlike the tatpp ligand, which is sparingly soluble in all common solvents. Photolysis of ditatpp with visible light in the presence of sacrificial donors, such as triethylamine, results in multi-electron reduction on each of the tatpp units, as determined by absorption spectroscopy. As the tatpp units appear to function independently of one another, and each tatpp unit is reduced by two electrons and is doubly protonated in the final compound, the photoreduction results in a net storage of 4 electrons in the fully reduced species.

\section{Introduction}

Photocatalysts capable of multi-electron storage are of particular interest, given the multi-electron nature of most fuel forming reactions. ${ }^{1-4}$ Historically, the majority of photo-catalysts developed for this purpose utilize precious metals, such as $\mathrm{Ru}, \mathrm{Re}$, and $\mathrm{Pt}$, which are scarce and expensive. ${ }^{3,5-16}$ As an alternative to using expensive transition metals, organic nitrogen-heterocycle chromophores, such as phenazine (phz) or dipyridophenazine (dppz), have also been shown to store multiple electrons upon photoreduction, however these chromophores typically absorb in the UV region of the spectrum. ${ }^{5,17,18}$ Ferraudi and coworkers ${ }^{19}$ describe the photoexcitation processes for these chromophores as occurring via a low-lying ${ }^{3}\left(\pi-\pi^{*}\right)$ state, which can undergo reductive quenching in the presence of sacrificial donors such as triethylamine (TEA) and triethanolamine (TEOA) to yield the radical species $\mathrm{dppz}^{\bullet}$ or $\mathrm{phz}^{\circ}$. Protonation of the resulting $\mathrm{dppz}^{\bullet}$ or $\mathrm{phz} \mathbf{z}^{\bullet}$ radicals results in disproportionation, yielding the doublyreduced, doubly-protonated products $\mathrm{dppz}_{2}$ or $\mathrm{phzH}_{2}$ and starting material, dppz or phz., ${ }^{5,18}$ The 
photoreduction is readily followed by appearance of a characteristic broad peak in the visible region at $400-550 \mathrm{~nm}$ and is associated with the doubly-reduced, doubly protonated compounds $\mathrm{dppz} \mathrm{H}_{2}$ or phz $\mathrm{H}_{2}$. The related tatpp nitrogen-heterocycle shows similar photochemistry with Guo and Obare reporting he two electron photoreduction to $\mathrm{H}_{2}$ tatpp in DMSO in the presence of TEA. ${ }^{20}$ Like dppz and phz, tatpp double reduction and protonation is accompanied by a broad new absorption growing in at $560 \mathrm{~nm}$ (DMSO, $\varepsilon=6500 \mathrm{M}^{-1} \mathrm{~cm}^{-1}$ ). Importantly, the tatpp ligand, with its extended aromatic system, is a visible light chromophore, with two strong sharp peaks at 435 and $460 \mathrm{~nm}$. Unfortunately, the sparing solubility of tatpp limits its study to dilute DMSO solutions, unless excess $\mathrm{Zn}(\mathrm{II})$ is added upon which the $\mathrm{Zn}$-tatpp$\mathrm{Zn}$ adducts exhibit decent solubility in alcohols and $\mathrm{MeCN} .^{21,22}$

We had previously shown that the tatpp ligand in $\left.\left[R u(\text { phen })_{2} \text { tatppRu(phen }\right)_{2}\right]^{4+}\left(\mathbf{P}^{4+}\right)$ acts as a twoelectron, two proton storage reservoir upon visible light irradiation of $\mathbf{P}^{4+}$ in water or $\mathrm{MeCN}$ in the presence of TEOA or TEA. ${ }^{14,16,23}$ Unlike the pure organic system, the second reduction may also be driven photochemically if the system $\mathrm{pH}$ is insufficient to protonate the radical intermediate $\mathbf{P}^{3+\bullet}{ }^{23,24}$ While the photochemistry of this compound is primarily thought to involve ${ }^{3} \mathrm{MLCT}$ excited states, a ${ }^{3}$ tatpp state is part of the excited state manifold, and is energetically near the lowest lying ${ }^{3}$ MLCT state ${ }^{25,26}$ As shown in Figure 1, the reductions are localized on the tatpp ligand and occur in a stepwise fashion. The identity of $\mathbf{P}^{3+\bullet}$, the doubly-reduced, singly-protonated $\mathbf{H P}^{3+}$, and doubly- reduced, doubly-protonated $\mathrm{H}_{2} \mathrm{P}^{4+}$ were all confirmed by following the spectral changes observed upon chemical titrations with cobaltocene and trifluoroacetic acid and with complementary spectroelectrochemical techniques. The most prominent spectral features for the radical $\mathbf{P}^{3+\bullet}$ being the appearance of a structured peak near 900 $\mathrm{nm}$ and for $\mathrm{H}_{2} \mathrm{P}^{4+}$ a new broad band at $560 \mathrm{~nm}$.

During large scale preparations of tatpp we discovered that dimer formation occurs, where tatpp monomer units are linked by a carbon-carbon bond between the central benzene unit of each ligand. Ditatpp formation is a minor side product, and demonstrates excellent solubility in common organic solvents. Because of lone pair repulsions, the two $\pi$-systems are nearly orthogonal to each other and thus, the tatpp subunits appear to act independently. In this work, we describe synthesis, characterization, and photochemistry of this soluble dimer, ditatpp, and demonstrate that visible-light photolysis of this compound leads to a four-electron reduction of the compound. The process can be 
reversed upon exposure to air, the ditatpp is reformed. Ditatpp is used to prepare the fully ruthenated tetramer, $\left[\left(\mathrm{Ru}(\text { phen })_{2}\right)_{4}(\right.$ ditatpp $\left.)\right]\left(\mathrm{PF}_{6}\right)_{8}$, which, while formed, is difficult to purify beyond $90 \%$ purity.

\section{Materials and Methods}

1,2,4,5-benzenetetramine tetrahydrochloride (BTA) (Sigma Aldrich, CAS: 4506-66-5) was purified according to literature procedures. ${ }^{27}$ 1,10-Phenanthroline-5,6-dione (phendione) was synthesized and purified according to literature procedures. ${ }^{13,28}$ All reactions were performed under aerobic conditions unless otherwise specified. All solvents were used without further purification.

\section{Synthesis of tatpp and ditatpp}

The standard preparation of tatpp according to literature procedures, ${ }^{13,28}$ was modified as described. BTA $(2.0 \mathrm{~g}, 7.0 \mathrm{mmol})$ was added to a $200 \mathrm{~mL}$ round bottom flask with $4.5 \mathrm{~g}$ phendione $(21.4$ $\mathrm{mmol}$ ), and $125 \mathrm{~mL}$ of dry ethanol. This solution was refluxed under $\mathrm{N}_{2}$ for 6 days without $\mathrm{K}_{2} \mathrm{CO}_{3}$, which is

usually present during tatpp preparation. ${ }^{13}$ The slurry was filtered with a medium porosity fritted funnel and the filter cake was washed with hot ethanol until no color eluted from solvent washings. The cake contains the crude tatpp whereas the filtrate contains the dimer ditatpp.

Isolation of tatpp: The filter cake was washed with $100 \mathrm{~mL}$ acetone, and transferred to a large beaker in which the solid was mulled with $16 \mathrm{~g} \mathrm{Zn}\left(\mathrm{BF}_{4}\right)_{2} \cdot \mathrm{xH}_{2} \mathrm{O}$ until a uniform paste had formed, after which $500 \mathrm{~mL}$ MeCN plus $10 \mathrm{~mL} \mathrm{H}_{2} \mathrm{O}$ was added. The solution was heated to reflux with constant stirring and the resulting solution filtered hot to remove undissolved solids. After cooling, $150 \mathrm{~mL}$ of $3 \mathrm{M} \mathrm{NaOH}$ was added to the solution and stirred for $1 \mathrm{~h}$, during which a dark solid precipitated from solution. The solution was filtered, and the precipitate washed with copious amounts of hot DI water. The filter cake was then washed with hot ethanol $(50 \mathrm{~mL})$, and a 1:1 mixture of dichloromethane/chloroform $(3 \times 100$ $\mathrm{mL}$ ), with special attention made to save all filtrate washings for use in isolation of ditatpp. A second wash was performed on the solid, using hot water $(100 \mathrm{~mL})$, ethanol $(100 \mathrm{~mL})$, dichloromethane $(100 \mathrm{~mL})$, and then dried in vacuo at $50^{\circ} \mathrm{C}$ for $24 \mathrm{hr}$, to afford $1.4 \mathrm{~g}$ tatpp (70\% yield). ${ }^{1} \mathrm{H}$ NMR $(500 \mathrm{MHz})$ was obtained 
in $\mathrm{MeCN}-d_{3}$ upon addition of an excess $\mathrm{Zn}\left(\mathrm{BF}_{4}\right)_{2}$ hydrate: $\delta=9.93(\mathrm{~d}, \mathrm{~J}=13.75 \mathrm{~Hz}, 4 \mathrm{H}), 9.58(\mathrm{~s}, 2 \mathrm{H})$, $9.25(\mathrm{~d}, \mathrm{~J}=8,4 \mathrm{H}), 8.32-8.28\left(\mathrm{dd}, \mathrm{J}_{1}=13.15, \mathrm{~J}_{2}=5,4 \mathrm{H}\right) \mathrm{ppm}$.

Isolation of ditatpp: The initial filtrate, plus the ethanol and 1:1 dichloromethane/chloroform washings were combined, and the solvent was removed under reduced pressure. The solids were redissolved in a minimal amount of ethanol $(\sim 5 \mathrm{~mL})$, and then precipitated by slow addition of up to $100 \mathrm{~mL}$ acetone. The solid obtained was filtered with a $0.2 \mu \mathrm{m}$ nylon membrane, then re-dissolved in a minimal amount of dichloromethane $(\sim 5 \mathrm{~mL})$. The solution was then passed through a glass wool plug in a disposable pipette to remove undissolved solids. Upon allowing the dichloromethane solution to evaporate, a dark red solid precipitated, which was isolated by filtration using a $0.2 \mu \mathrm{m}$ nylon membrane. The solid was washed with $10 \mathrm{~mL} 90: 10$ acetone/ethanol, then dried in a vacuo at $50^{\circ} \mathrm{C}$ for $24 \mathrm{hr}$, to yield the ditatpp, $55 \mathrm{mg}\left(0.73 \%\right.$ yield). ${ }^{1} \mathrm{H}$ NMR $\left(500 \mathrm{MHz} \mathrm{CDCl}_{3}-d_{1}\right): \delta=9.95(\mathrm{~s}, 2 \mathrm{H}), 9.87(\mathrm{~d}, \mathrm{~J}=9.6,4 \mathrm{H})$, $9.26(\mathrm{~d}, \mathrm{~J}=6.2 \mathrm{~Hz}, 4 \mathrm{H}), 8.93(\mathrm{~d}, \mathrm{~J}=6.5 \mathrm{~Hz}, 4 \mathrm{H}), 8.21(\mathrm{~d}, \mathrm{~J}=9.6 \mathrm{~Hz}, 4 \mathrm{H}), 7.89(\mathrm{dd}, \mathrm{J}=12.7 \mathrm{~Hz}$ and 3.8 $\mathrm{Hz}, 4 \mathrm{H}), 7.17$ (dd, $\mathrm{J}=12.7 \mathrm{~Hz}$ and $3.4 \mathrm{~Hz}, 4 \mathrm{H})$ ppm. MALDI-TOF: [(M + $\left.\left.2 \mathrm{Na}^{+}\right)\right]^{+}$: calc: $1016.9 \mathrm{~m} / \mathrm{z}$, found: $1017.6 \mathrm{~m} / \mathrm{z}$. X-ray quality crystals were grown by layering toluene on $\mathrm{CH}_{2} \mathrm{Cl}_{2}$ solution (1:3) of ditatpp.

Synthesis of $\left[\left(R u(p h e n)_{2}\right)_{4}(\right.$ ditatpp $\left.)\right]\left(P F_{6}\right)_{8}$

Ditatpp $(90.0 \mathrm{mg}, 92.8 \mu \mathrm{mol})$ was added to freshly prepared $\left[\mathrm{Ru}(\text { phen })_{2}\right] \mathrm{Cl}_{2}(230 \mathrm{mg}, 432 \mu \mathrm{mol}$, 4.6 equiv) $)^{29}$ in $100 \mathrm{~mL}$ of $\mathrm{EtOH}$ under $\mathrm{N}_{2}$, and refluxed for 48 hours. The solution was cooled, filtered with a $0.2 \mu \mathrm{m}$ nylon membrane, and $100 \mathrm{~mL} \mathrm{H}_{2} \mathrm{O}$ was added to the filtrate. $\mathrm{NH}_{4} \mathrm{PF}_{6}$ was added in excess to precipitate a nearly black solid which was filtered with a $0.2 \mu \mathrm{m}$ nylon membrane and dried in a vacuo at $50{ }^{\circ} \mathrm{C}$ for $24 \mathrm{hr}$. The product was purified by double metathesis: First the crude product was dissolved in acetone $(20 \mathrm{~mL})$, filtered, and the chloride salt precipitated by dropwise addition of a saturated acetone solution of tetrabutylammonium chloride $\left(\mathrm{Bu}_{4}{ }_{4} \mathrm{NCl}\right)$. The resulting precipitate was filtered, washed with fresh acetone, and dried at $50^{\circ} \mathrm{C}$ for $24 \mathrm{hr}$. The nearly black solid was then dissolved in $20 \mathrm{~mL} \mathrm{D.I.} \mathrm{H}_{2} \mathrm{O}$, filtered, and dropwise addition of a saturated aqueous ammonium hexafluorophosphate solution resulted in the precipitation of the hexafluorophosphate salt. The precipitate was filtered, washed with water and then diethyl ether and dried in a vacuo at $50{ }^{\circ} \mathrm{C}$ for $24 \mathrm{hr}$. This process was repeated two more times to

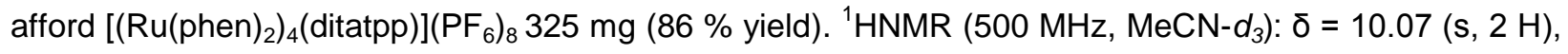


9.75-9.67 (m, $5 \mathrm{H})$, 8.6-7.08 (m, $134 \mathrm{H})$ ppm. ESI-MS: $\left(\mathrm{M}-3 \mathrm{PF}_{6}\right)^{3+},\left(\mathrm{M}-4 \mathrm{PF}_{6}\right)^{4+},\left(\mathrm{M}-5 \mathrm{PF}_{6}\right)^{5+},(\mathrm{M}-6$ $\left.\mathrm{PF}_{6}\right)^{6+},\left(\mathrm{M}-7 \mathrm{PF}_{6}\right)^{7+},\left(\mathrm{M}-8 \mathrm{PF}_{6}\right)^{8+}$ calc: $1181.67,850.07,651.73,518.47,423.73 \mathrm{~m} / \mathrm{z}$ found: 1181.67 , $850.07,651.73,518.47,423.73,352.67 \mathrm{~m} / \mathrm{z}$.

$X$-ray Crystallography: The solvent system was highly volatile therefore, the crystals were acutely airsensitive. Crystals began to de-solvate only seconds after removing from the mother liquor and mounting of the crystals was executed hastily. Crystals were drawn out of their vials using a pipette, and placed onto a glass slide previously stored in a freezer. The crystals themselves were visibly twinned and time did not allow proper removal of twinned crystals by cutting. A large twinned crystal was mounted onto a cyro-loop and data was collect under cold nitrogen flow at $100 \mathrm{~K}$. A unit cell determination failed because of the twinning problem, however the data was de-twinned using the software Cell_Now provided by Bruker-AXS. ${ }^{30} \mathrm{~A}$ reasonable cell was selected by calculating the volume of the putative structure and data was collected for a period of 18 hours. The complete data set was processed using the SAINT (version 6.45) and TWINABS software provided by Bruker-AXS. ${ }^{30}$ An hklf4 and hklf5 reflection file was generated and the hklf4 file was used to solve the structure. Later, towards the end of the refinement, the hklf5 reflection file was used to finalize the refinement. The non-hydrogen atoms are refined anisotropically and hydrogen atoms were added in calculated positions. Co-crystalized toluene and dichloromethane molecules were found in the unit cell. The disorder of the solvent molecules were solved with a combination of restraints: dfix, dang and anisotropic parameters. The final agreement factors are admittedly high but attempts to recollect on a better quality crystal were unsuccessful due to the highly volatile nature of the samples. However, the spacegroup and structure are unambiguous and clearly show evidence of a dimeric structure and the dihedral angle is well determined. Full crystallographic details and tables containing bond distances and angles are located in Supporting Information.

Photochemistry: A stock solution of ditatpp was prepared by diluting $1.27 \mathrm{mg}$ of material in a $50.00 \mathrm{~mL}$ volumetric flask with $100 \% \mathrm{EtOH}$. Aliquots $(3.0 \mathrm{~mL})$ of the stock solution were transferred to freshly cleaned quartz cuvettes $(b=1 \mathrm{~cm})$ which were fitted with a screw cap and septum seal. Prior to addition of TEA, the solution was de-gassed with $\mathrm{N}_{2}$, and the initial UV/Vis spectra was obtained using a Hewlett Packard 8453 UV-Visible Spectrophotometer. While continually de-gassing the solution, $0.1 \mathrm{~mL}$ TEA was 
added slowly. Samples were then irradiated using a custom light source $\left(\lambda_{\max }=470 \mathrm{~nm}\right)$ previously described in the literature. ${ }^{24,31}$ Chemical actinometry using potassium ferrioxalate ${ }^{32}$ gave an average photon flux of $36 \times 10^{-3}$ Einstein $\mathrm{h}^{-1}$. After photolysis was complete, samples were exposed to $\mathrm{O}_{2}$ by using a pipette to bubble air through the solution which was then allowed to rest 5 minutes prior to final spectral analyses.

\section{Results and Discussion}

The ditatpp dimer is a minor byproduct formed during the preparation of the free tatpp ligand and is only isolated in less than $1 \%$ yield. Unlike tatpp, the dimer ditatpp is freely soluble in numerous organic solvents and was only discovered by chance, as the common purification procedure for tatpp involved extensive washings which were typically discarded. While the exact mechanism of formation is unclear, it seems reasonable that tatpp in solution may be reduced by some benzene-tetrammine to form a radical species that couples at the bridgehead position, and is then re-aromatized upon oxidation by reaction with phendione. Reaction run under aerobic conditions did not yield any ditatpp but gave similar yields of tatpp.

The ${ }^{1} \mathrm{H}$ NMR of the tatpp and ditatpp are shown in Figure 2. All of the hydrogens are attached to aromatic rings and, as expected, found in the downfield aromatic region. Both molecules have $D_{2 \mathrm{~h}}$ point group symmetry however, the dimer has 7 unique hydrogens and while the monomer only has 4 . This is clearly observed in the NMR spectrum with tatpp showing a single AMX coupled set for $H_{a}, H_{b}$, and $H_{c}$ plus the singlet for the central $H_{d}$. The dimer ditatpp has an inner AMX coupled set $\left(H_{f}, H_{g}, H_{h}\right)$ and outer A'M'X' coupled set $\left(H_{a}, H_{b}\right.$, and $\left.H_{c}\right)$ plus the central $H_{d}$ singlet. Integration shows that the ratio of $H_{d}$ to $H_{a}$ (or any of the other hydrogens) of 1:2 for tatpp and ditatpp as expected. Due to the poor solubility of tatpp, its spectrum required addition of an excess of $\mathrm{Zn}\left(\mathrm{BF}_{4}\right)_{2}$ to solubilize the ligand in $\mathrm{MeCN}-\mathrm{d}_{3}$, while the ditatpp dimer was freely soluble in $\mathrm{CDCl}_{3}$. Unfortunately, this solvent change makes direct comparisons of the chemical shifts relatively meaningless as large shifts are observed upon changing solvents. It suffices to say, the NMR are completely compatible with the proposed structures.

Single crystal X-ray crystallography of the ditatpp crystal showed that it crystalized in a triclinic system with a $\mathrm{P} \overline{1}$ space group. This structure shows a ditatpp molecule co-crystallized with six dichloromethane and five toluene solvent molecules in the asymmetric unit. As seen in Figure 3 , the 
dimeric structure is readily apparent and the central C-C bond distance of $1.496 \AA$, which is very similar to the related $\mathrm{C}-\mathrm{C}$ bond distance reported for an anthracene dimer. ${ }^{33}$ The dihedral angle of the planar aromatic units about the $\mathrm{C}-\mathrm{C}$ bond in ditatpp is $73^{\circ}$, whereas the same angle for the anthracene dimer is $80^{\circ}$. The increased twisting in tatpp indicates that the aza nitrogen lone pair repulsion is not as strong a steric restraint as having hydrogens in these locations. While the dihedral angle in the crystal structure is fixed, in solution the average dihedral angle averages $90^{\circ}$ as there is freedom to expand the dihedral angle but not to compress it. At $90^{\circ}$, the two orthogonal $\pi$ systems will have zero electronic overlap, suggesting that the two chromophore units will largely behave independently.

The $\left[\left(\mathrm{Ru}(\text { phen })_{2}\right)_{4}(\right.$ ditatpp $\left.)\right]\left(\mathrm{PF}_{6}\right)_{8}$ complex was prepared by reaction of the free ditatpp ligand with a slight excess of $\mathrm{Ru}(\text { phen })_{2} \mathrm{Cl}_{2}$ in refluxing ethanol. The complex was purified by repeated metathesis between the chloride and hexafluorophosphate salt. The final product shows the parent peaks in the ESI-MS, and the ${ }^{1} \mathrm{H}$ NMR spectrum, shown in Figure 4, reveals a number of new peaks that would at first appear to be impurities, as indicated by the asterisks. However, careful analysis of the downfield region indicates that some, if not all of these peaks are due to the stereochemical heterogeneity of the product. Each metal center can exist in either the $\Lambda$ or $\Delta$ stereochemical configuration giving rise to a $2^{n}(n=4)$ mixture of enantiomers and diasteromers, the latter of which could be expected to have different chemical shifts between diasteromers. Previous studies on tatpp dimers as well as dimers with shorter tetrapyridophenazine (tpphz) ligands have shown that the stereochemical isomerism is not detectable in simple linear dimers, as the stereocenters are anywhere from $12 \mathrm{~A}$ (in tpphz dimers) to $17 \mathrm{~A}$ (in tatpp dimers) and cannot approach any closer. ${ }^{34-38}$ This is not exactly the case with the tetramer in which stereocenters on the same tatpp portion are still spatially separated, however, stereocenters on adjacent tatpp units can and do interact. This is most readily observed in the downfield doublets at 9.66, 9.70, and 9.74 ppm, which are present in a 2:4:2 ratio. If the inner $\mathrm{H}_{e}$ and outer $\mathrm{H}_{c}$ hydrogens were magnetically equivalent, only two doublets of equal intensity should be observed. The $H_{d}$ singlet at $10.1 \mathrm{ppm}$ reveals that for this position, the metal stereochemistry is irrelevant, however the adjacent three doublets can only be explained if we obtain different chemical shifts for cases in which adjacent centers are homochiral $(\Delta \Delta$ or $\Lambda \Lambda)$ or heterochiral $(\Delta \Lambda$ or $\Lambda \Delta)$. As these are expected to be present in a 1:1 ratio, the $H_{e}$ peak is now observed as a doublet at either 9.66 or $9.74 \mathrm{ppm}$ whereas the outer $\mathrm{H}_{\mathrm{c}}$ is seen at 9.70 regardless of the 
stereochemistry. The chemical shifts between diastereomers differ the greatest for the $\mathrm{H}_{\mathrm{e}}, \mathrm{H}_{\mathrm{f}}$ and $\mathrm{H}_{g}$ tatpp hydrogens, as well as the hydrogens on the phenanthrolines on the inner-side of the complex. Conversely, the $\mathrm{H}_{a}, \mathrm{H}_{b}$, and $\mathrm{H}_{c}$ are the least affected, being the furthest spatially from the site of where the two stereocenters interact.

The absorption spectrum of the free ditatpp dimer in ethanol and the associated changes upon irradiation with visible light in the presence of TEA are shown in Figure 5. The spectrum of ditatpp mirrors that seen for tatpp, obtained as the $\mathrm{Zn}$ (II) complex in $\mathrm{MeCN}$, with a large sharp peak in the UV at $350 \mathrm{~nm}$ and a structured band in the visible with peaks at $409 \mathrm{~nm}, 433 \mathrm{~nm}$, and $460 \mathrm{~nm}$. This latter band is assigned as a $\pi-\pi$ transition. ${ }^{39}$ The molar absorptivity of the ditatpp dimer at the highest visible peak (ethanol, $\lambda_{\max } 460 \mathrm{~nm}, \varepsilon=34,300 \mathrm{M}^{-1} \mathrm{~cm}^{-1}$ ) is almost twice that of the $\mathrm{Zn}(\mathrm{II})$ adduct of tatpp at its highest visible peak (wet MeCN, $\lambda_{\max } 445 \mathrm{~nm}, \varepsilon=17300 \mathrm{M}^{-1} \mathrm{~cm}^{-1}$ ). ${ }^{39}$ The free tatpp ligand is slightly soluble in DMSO and is reported to have two peaks in the visible region at 435 and $460 \mathrm{~nm}$, the latter having a molar extinction coefficient of $10,300 \mathrm{M}^{-1} \mathrm{~cm}^{-1}$ at $460 \mathrm{~nm}^{.20}$ The cause of the discrepancies in peak maxima and molar extinction coefficient could be due to a number of factors including the change in solvent, the presence or absence of the $\mathrm{Zn}(\mathrm{II})$ or the difficulty of completely dissolving tatpp, even in DMSO. We postulate that $\mathrm{Zn}(\mathrm{II})$ coordination causes a blue shift in the $\pi-\pi$ transition due to electron withdrawing effects and it helps to breaks up any $\pi-\pi$ stacking, which can cause hypochromism and is the likely cause of the lower than expected molar extinction coefficient for tatpp in DMSO. It suffices to say that the differences between tatpp and ditatpp are not very large and to a first approximation, the two $\pi$ systems in ditatpp appear to be electronically uncoupled.

As shown in Figure 5, upon irradiation of degassed ethanol solutions in the presence of TEA (0.2 M), the ditatpp dimer spectrum shows a gradual bleach of the peaks in 405-460 $\mathrm{nm}$ region and the appearance of a broad new peak centered at $560 \mathrm{~nm}$, which is assigned to formation of the doublyreduced, doubly-protonated tatpp unit. ${ }^{14,15}$ While the ethanolic solution does not contain acidic protons, such protons are generated quantitatively via the decomposition of the TEA ${ }^{+}$radical cation, ${ }^{40}$ which is generated upon reductive quenching of the photoexcited ditatpp by the TEA. The broad, almost double- 
humped peak in the 500-600 region is characteristic of the quadruply reduced and protonated $\mathrm{H}_{4}$ ditatpp, which is shown in the inset in Figure 5. This feature is also seen in the $\mathrm{Zn}$ (II) and $\mathrm{Ru}$ (II) adducts of tatpp upon double-reduction to the $\mathrm{H}_{2}$ tatpp complexes..$^{20-22,41}$ The magnitude of the $560 \mathrm{~nm}$ peak relative to the bleach at $460 \mathrm{~nm}$ is indicative that both tatpp units in ditatpp have undergone double-reduction or a net 4 electron reduction overall to yield $\mathrm{H}_{4}$ ditatpp. The quadruply-reduced product is stable for hours in solution but upon addition of $\mathrm{O}_{2}$ is rapidly reoxidized to principally to starting material. As seen by the rise in the baseline of the reoxidized species, the reaction is not completely reversible and an estimated $10 \%$ of the starting material is lost to side reactions. Notably, during the photoreduction and even after 830 seconds of photolysis, two small but significant peaks are observed in the $800-1000 \mathrm{~nm}$ region. Peaks in this region are indicative of the tatpp radical anion in $\mathbf{P}^{3+\bullet}$ (see Figure 1$)^{14,16}$ and are presumably due to the presence of the ditatpp.- or ditatpp...2- radical intermediates. which are presumably formed and consumed rapidly as the photolysis proceeds.

The photoreduction product is shown in Figure 6 as the tetrahydro species drawn in the benzoid tautomeric form. It is possible that the complex would prefer the quinoid tautomer, however for spatial reasons only, one tautomer is shown. The reduction is reversible and thus it is possible that ditatpp could be used in a photocatalytic manner. The ditatpp dimer has a number of properties that make it an exciting chromophore for potential light-to-chemical energy conversion schemes. It is freely soluble, contains no expensive or rare metal ions, absorbs in the visible region, and photochemically and reversibly stores up to 4 electrons and protons. These features will be explored in the context of solar energy conversion.

\section{Acknowledgements}

We thank the National Science Foundation CHE1301332 (FMM) and the Robert A. Welch Foundation Y1301 (FMM) for financial support. We also thank Dr. Shreeyukta Singh and Abhishek Yadav for their assistance and helpful discussions.

Keywords: multi-electron storage, photoreduction, visible chromophore, ruthenium polypyridyl complexes 


\section{References}

(1) Lewis, N. S.; Nocera, D. G. Proc. Nat. Acad.Sci. 2006, 103, 15729.

(2) Esswein, A. J.; Nocera, D. G. Chem. Rev. 2007, 107, 4022.

(3) MacDonnell, F. M. Solar Hydrogen GenerationToward a Renewable Energy Future; Springer New York, 2008.

(4) van de Krol, R.; Grätzel, M. Photoelectrochemical Hydrogen Production; Springer, 2011.

(5) Fees, J.; Kaim, W.; Moscherosch, M.; Matheis, W.; Klima, J.; Krejcik, M.; Zalis, S. Inorg. Chem. 1993, 32, 166.

(6) Fees, J.; Ketterle, M.; Klein, A.; Fiedler, J.; Kaim, W. J. Chem. Soc., Dalton Trans. 1999, 2595.

(7) Molnar, S. M.; Nallas, G.; Bridgewater, J. S.; Brewer, K. J. J. Am. Chem. Soc. 1994, 116, 5206.

(8) Brewer, K. J. B., VA, US), Elvington, Mark (Blacksburg, VA, US); Virginia Tech Intellectual Properties, Inc. (Blacksburg, VA, US): United States, 2009.

(9) Choi, C.-S.; Mutai, T.; Arita, S.; Araki, K. J. Chem. Soc., Perkin Trans. 2 2000, 243.

(10) Olofsson, J.; Önfelt, B.; Lincoln, P. J. Phys. Chem. A 2004, 108, 4391.

(11) Tan, L. F.; Liang, X. L.; Liu, X. H. J. Inorg. Biochem. 2009, 103, 441.

(12) Kuhnt, C.; Karnahl, M.; Tschierlei, S.; Griebenow, K.; Schmitt, M.; Schafer, B.; Krieck, S.; Gorls, H.; Rau, S.; Dietzek, B.; Popp, J. Phys. Chem. Chem. Phys. 2010, 12, 1357.

(13) Kim, M. J.; Konduri, R.; Ye, H.; MacDonnell, F. M.; Puntoriero, F.; Serroni, S.; Campagna, S.; Holder, T.; Kinsel, G.; Rajeshwar, K. Inorg. Chem. 2002, 41, 2471.

(14) de Tacconi, N. R.; Lezna, R. O.; Konduri, R.; Ongeri, F.; Rajeshwar, K.; MacDonnell, F. M. Chem. Eur. J. 2005, 11, 4327.

(15) de Tacconi, N. R.; Chitakunye, R.; MacDonnell, F. M.; Lezna, R. O. J. Phys. Chem. A 2008, 112, 497.

(16) Lezna, R. O.; Tacconi, N. R.; Janaratne, T.; Zuniga, M.; MacDonnell, F. M. J. Argent. Chem. Soc. $2009,97$.

(17) McGovern, D. A.; Selmi, A.; O'Brien, J. E.; Kelly, J. M.; Long, C. Chem. Commun. (Camb) 2005, 1402.

(18) Fukuzumi, S.; Koumitsu, S.; Hironaka, K.; Tanaka, T. J. Am. Chem. Soc. 1987, 109, 305.

(19) Ruiz, G. T.; Juliarena, M. P.; Lezna, R. O.; Feliz, M. R.; Ferraudi, G. J. Photochem. Photobiol., A 2006, 179, 289.

(20) Guo, W.; Obare, S. O. Tet. Lett. 2008, 49, 4933.

(21) Konduri, R.; de, T. N. R.; Rajeshwar, K.; MacDonnell, F. M. J. Am. Chem. Soc. 2004, I $126,11621$.

(22) de Tacconi, N. R.; Lezna, R. O.; Konduri, R.; Ongeri, F.; Rajeshwar, K.; MacDonnell, F. M. Chem. Eur. J. 2005, 11, 4327.

(23) Konduri, R.; Ye, H.; MacDonnell, F. M.; Serroni, S.; Campagna, S.; Rajeshwar, K. Angew. Chem., Int. Ed. 2002, 41, 3185.

(24) Aslan, J. M.; Boston, D. J.; MacDonnell, F. M. Chem. Eur. J. 2015, 21, 17314.

(25) Chiorboli, C.; Fracasso, S.; Scandola, F.; Campagna, S.; Serroni, S.; Konduri, R.; MacDonnell, F. M. Chem. Commun. (Cambridge, U. K.) 2003, 1658.

(26) Majewski, M. B.; de, T. N. R.; MacDonnell, F. M.; Wolf, M. O. Chem. Eur. J. 2013, 19, 8331.

(27) Gajiwala, H. M.; Zand, R. Polymer 2000, 41, 2009.

(28) Zheng, R. H.; Guo, H. C.; Jiang, H. J.; Xu, K. H.; Liu, B. B.; Sun, W. L.; Shen, Z. Q. Chin. Chem. Lett. 2010, 21, 1270.

(29) Giordano, P. J.; Bock, C. R.; Wrighton, M. S. J. Am. Chem. Soc. 1978, 100, 6960.

(30) Sheldrick, G. M.SHELXTL, version 6.14; Bruker Analytical X-ray Systems, Inc.; Madison, WI, 2000.

(31) Boston, D. J.; Xu, C.; Armstrong, D. W.; MacDonnell, F. M. J. Am. Chem. Soc. 2013, 135, 
16252.

(32) Kuhn, H. J.; Braslavsky, S. E.; Schmidt, R. Pure Appl. Chem. 2004, 76, 2105.

(33) Kyzioł, J. B.; Zaleski, J. Acta Crystallogr., Sect. E: Struct. Rep. Online 2007, 63, 1235.

(34) Bolger, J.; Gourdon, A.; Ishow, E.; Launay, J.-P. J. Chem. Soc., Chem. Comm. 1995, 17, 1799.

(35) Ishow, E.; Gourdon, A.; Launay, J.-P.; Lecante, P.; Verelst, M.; Chiorboli, C.; Scandola, F.; Bignozzi, C.-A. Inorg. Chem. 1998, 37, 3603.

(36) MacDonnell, F. M.; Bodige, S. Inorg. Chem. 1996, 35, 5758.

(37) Bodige, S.; Torres, A. S.; Maloney, D. J.; Tate, D.; Kinsel, G.; Walker, A.; MacDonnell, F. M. J. Am. Chem. Soc. 1997, 119, 10364.

(38) Kim, M.-J.; Konduri, R.; Ye, H.; MacDonnell, F. M.; Puntoriero, F.; Serroni, S.; Campagna, S.; Holder, T.; Kinsel, G.; Rajeshwar, K. Inorg Chem 2002, 41, 2471.

(39) Singh, S.; de, T. N. R.; Boston, D.; MacDonnell, F. M. Dalton Trans. 2010, 39, 11180.

(40) DeLaive, P. J.; Lee, J. T.; Sprintschnik, H. W.; Abruna, H.; Meyer, T. J.; Whitten, D. G. J. Am. Chem. Soc. 1977, 99, 7094.

(41) de Tacconi, N. R.; Lezna, R. O.; Chitakunye, R.; MacDonnell, F. M. Inorg. Chem. 2008, 47, 8847. 


\section{Figure Captions:}

Figure 1. Two electron reduction of the ruthenium-tatpp dimer and the associated nomenclature to indicate the ligand redox and protonation state.

Figure 2. ${ }^{1} \mathrm{H}-\mathrm{NMR}$ of tatpp monomer (top) and ditatpp dimer (bottom). [a] prepared using $\mathrm{d}_{3}-\mathrm{MeCN}$ and $\left[\mathrm{Zn}\left(\mathrm{BF}_{4}\right)_{2}\right]$ then filtered. [b] prepared using neat $d_{1}-C D C l$

Figure 3. Crystal structure of ditatpp at varying angles with solvent removed and axis added for clarity. The crystal has a triclinic unit cell with a $\mathrm{P} \overline{1}$ space group.

Figure 4. ${ }^{1} \mathrm{HNMR}$ of the tetranuclear complex $\left[\left(\mathrm{Ru}(\text { phen })_{2}\right)_{4}(\mathrm{ditatpp})\right]\left(\mathrm{PF}_{6}\right)_{8}$ in $\mathrm{CD}_{3} \mathrm{CN}$ in the aromatic region. $\left({ }^{*}\right)$ indicate the splitting of the larger peaks due to the stereochemical heterogenaity of the complex.

Figure 5. Photolysis of ditatpp $(26 \mu \mathrm{M})$ at $470 \mathrm{~nm}$ in ethanol with $240 \mathrm{mM}$ TEA as a sacrificial donor as a function of time. $\mathrm{O}_{2}$ added indicates reveals the process is largely reversible. Inset: Chemical reduction $25 \mu \mathrm{M}$ ditatpp in $\mathrm{H}_{2} \mathrm{O}: \mathrm{EtOH}(1: 3)$ plus $10 \mathrm{mM}$ ascorbic acid to form $\mathrm{H}_{4}$ ditatpp.

Figure 6. Chemical structure of ditatpp and the quadruply reduced $\mathrm{H}_{4}$ ditatpp 
Fig 1

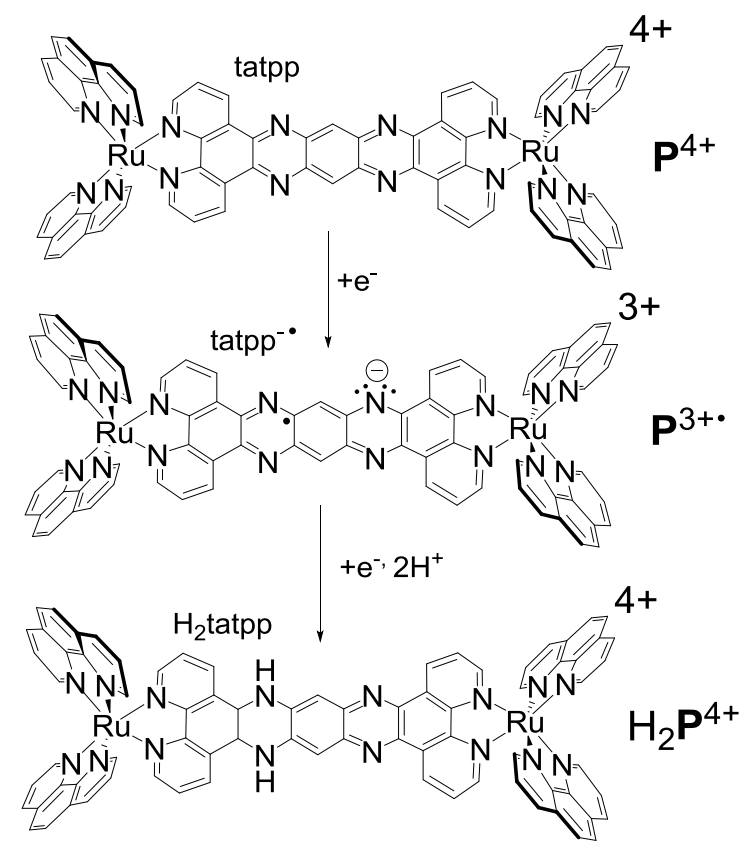


Fig 2

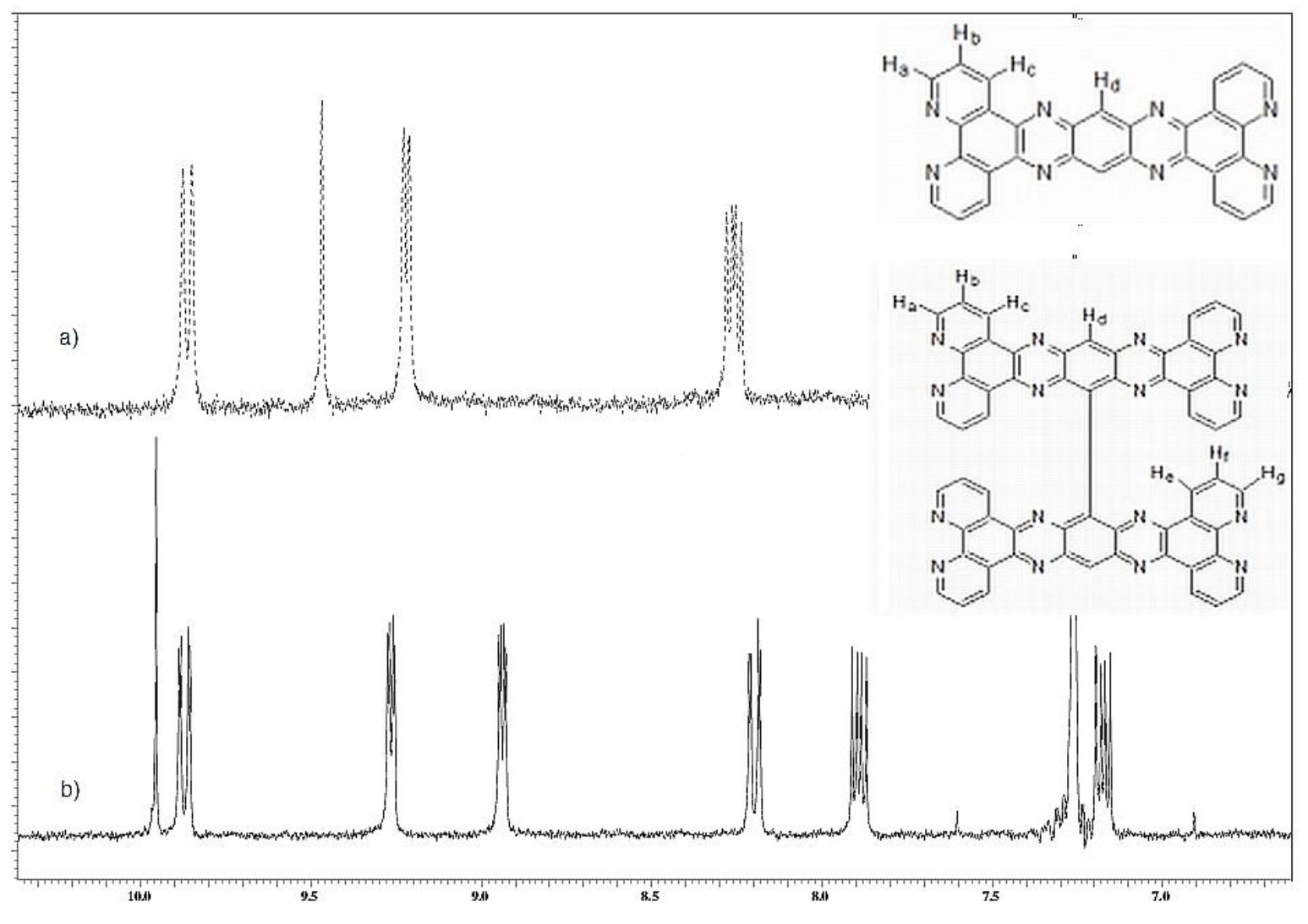


Fig 3
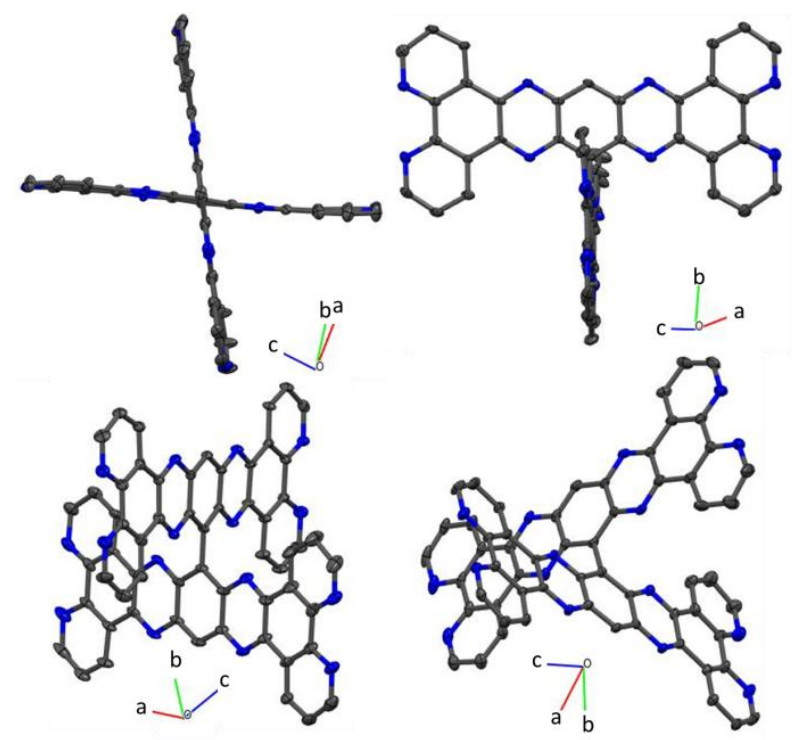
Fig 4

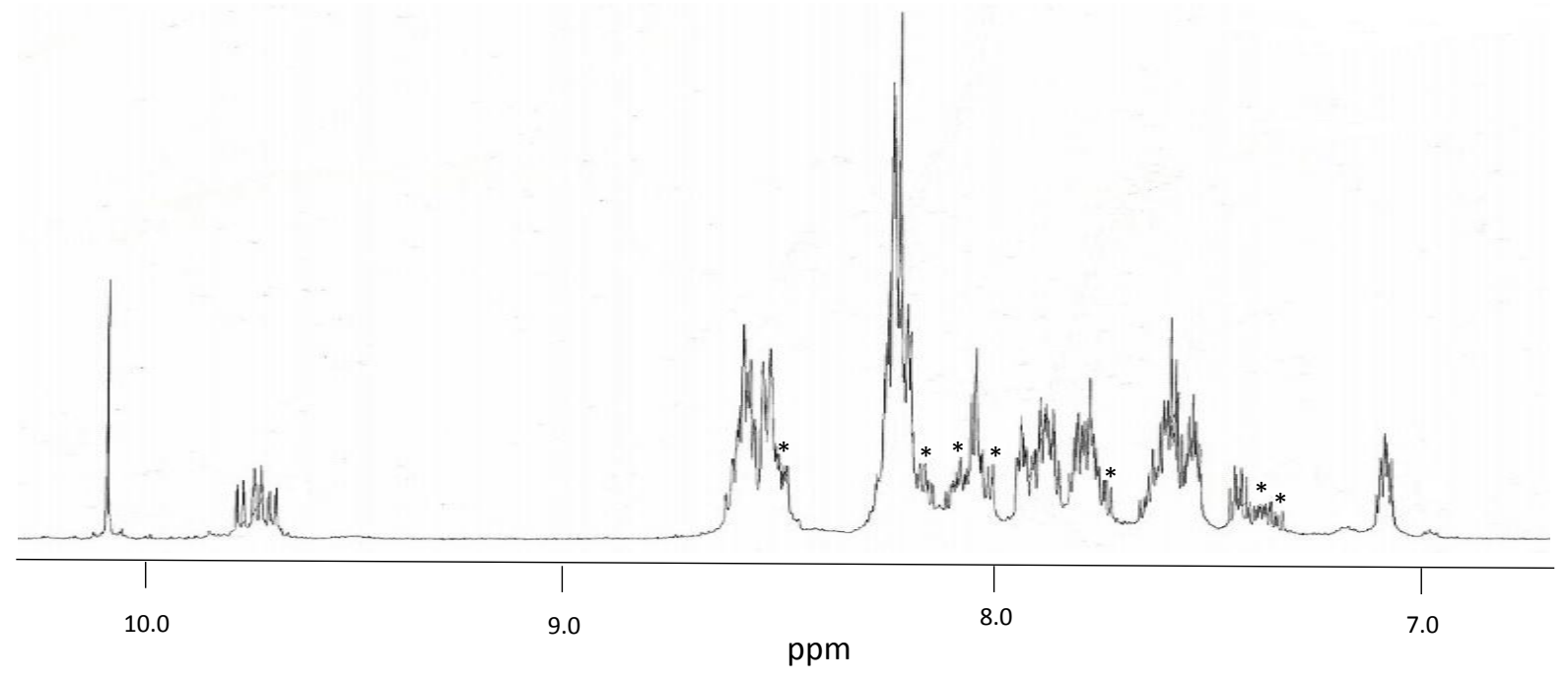


Fig 5

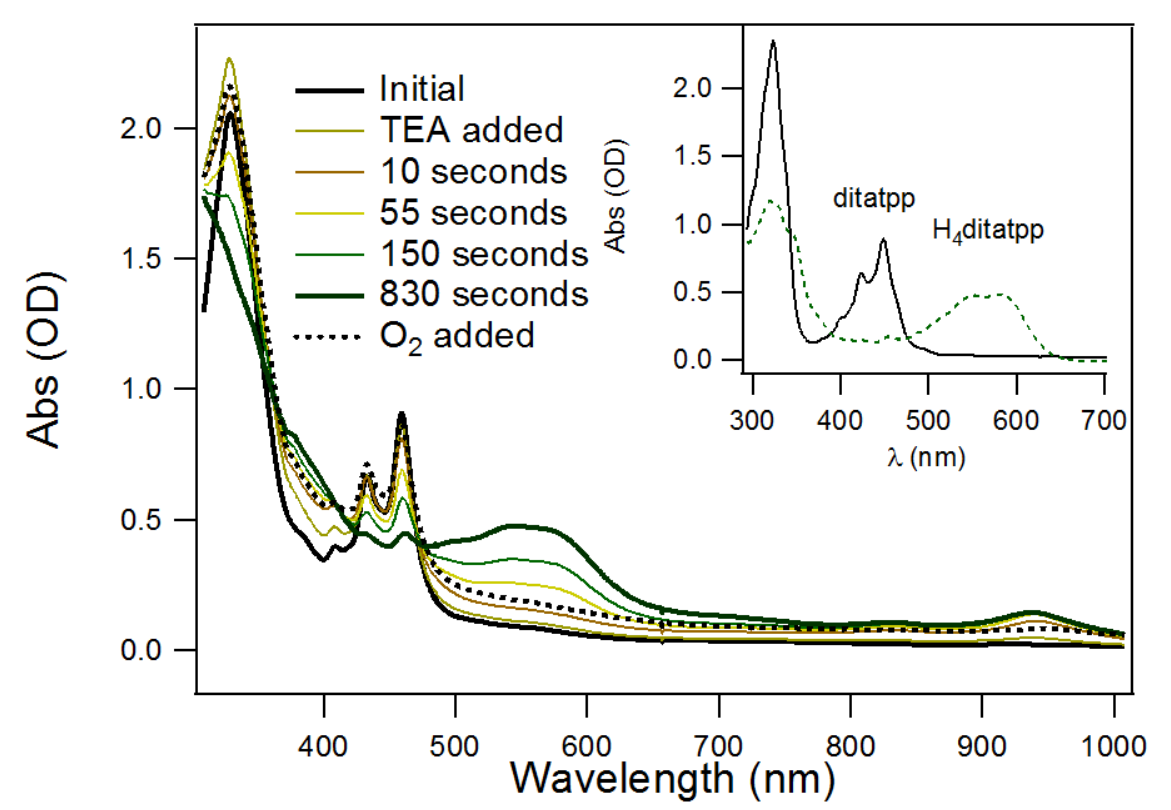


Fig 6.

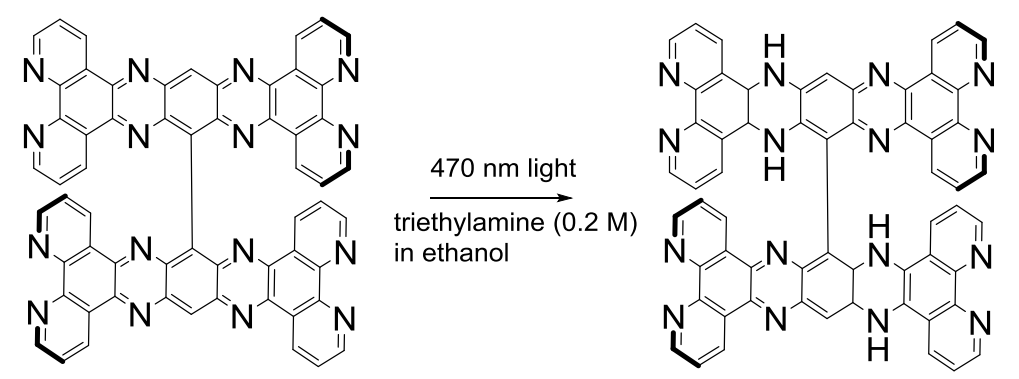


Visible light irradiation of the soluble di-tetraazatetrapyridopentacene chromophore in the presence of sacrificial amine donors generates the quadruply reduced compound, storing, in principle, two moles of $\mathrm{H}_{2}$. 


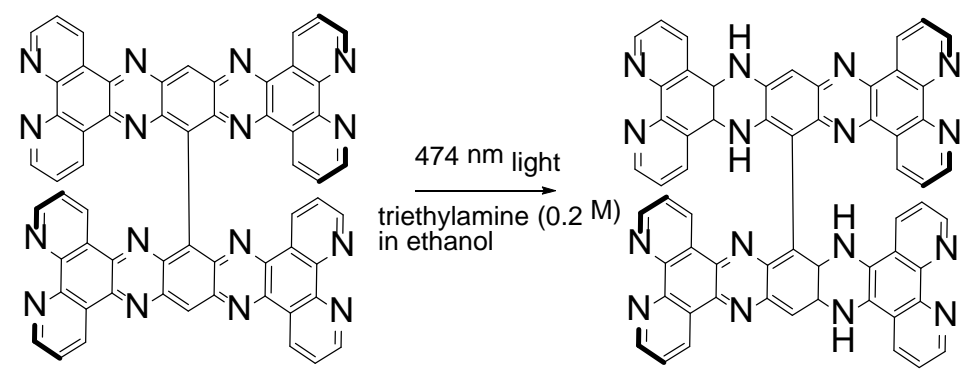

